\title{
DEBATE
}

\section{Persistent toxic chemicals: more than Stockholm persistent organic pollutants}

\section{G Bengtsson}

J Epidemiol Community Health 2002;56:833-834

Schafer and Kegley bring up the important issue of excessive chemicals exposure of children. However, they do not consider in depth the "cumulative and simultaneous exposures faced by children, (...) moving beyond the chemical-by-chemical approach of the past", as quoted from the US Environmental Protection Agency national agenda to protect children from environmental health threats. Existing evidence for contamination by many substances beyond those dealt with in the article calls for additional protective measures. These could include an extra margin of exposure by a factor of 10 to cover cumulation of chemicals, for adults and children alike.

Correspondence to: Gunnar Bengtsson, Swedish National Chemicals Inspectorate, Box 1384, S-17127 Solna Sweden; Gunnarb@kemi.se
O ne of the prominent issues that Schafer and Kegley ${ }^{1}$ bring up is the strong concern about hazardous chemicals in children's food. They show that levels of the 12 substances covered by the Stockholm Convention on persistent organic pollutants (POPs) may exceed the reference dose for children. Those substances are, however, only the tip of the iceberg: there are several reasons for even greater concern.

\section{THE NEED TO INCLUDE ALL RELEVANT SUBSTANCES}

The United States Environmental Protection Agency (EPA) National Agenda to Protect Children From Environmental Health Threats ${ }^{2}$ (item 3) recognises the need to tackle the "cumulative and simultaneous exposures faced by children, (...) not just the chemical-by- chemical approach of the past". There are two distinct reasons to go beyond the Stockholm POPs in adhering to this agenda item:

(1) The 12 mentioned substances represent a fraction of those substances that by the Convention criteria are very persistent (half life in soil or sediment over six months) and very bioaccumulating (bio-concentration fish to water over 5000). Many more substances meet those criteria.

(2) The criteria were set by negotiation, not by what happens in nature. In Europe, considerably stricter criteria are being discussed. Criteria proposed by Sweden, for instance, would encompass about $10 \%$ of all industrial chemicals on the market, or 100-fold more substances than the Stockholm POPs. A couple of examples may serve to support the notion of contamination by many substances, in addition to the hundreds of breast milk contaminants implicitly mentioned by Schafer and Kegley. ${ }^{1}$ According to a recent study, ${ }^{3}$ in US natural water streams up to 38 substances out of 95 analysed were simultaneously present in detectable amounts. In Swedish human blood ${ }^{4}$ more than 100 phenolic chlorinated or brominated substances were detected.

\section{THE NEED TO INCLUDE ALL RELEVANT EXPOSURES OVER TIME}

Persistent substances may be lost to the biosphere by degradation or incorporation in sinks. The fraction that is not lost should be seen as causing exposure sooner or later. In the absence of information to the contrary, all material that is produced by humans should be assumed to become released sooner or later. In the field of radiation protection, the concept of committed dose covers the dose that is caused at one point in time even though exposures may occur later. For a continuing practice, the annual committed dose will be equal to the equilibrium annual actual dose.

\section{ADD INCREMENTAL EXPOSURES FROM MANY SUBSTANCES TO YIELD INCREMENTAL RESPONSES}

It has recently been shown ${ }^{5}$ that the response of several substances may be best described by adding their amounts as weighted by their toxicity equivalency factors. A similar assumption seems even more reasonable in a very complex environment with children of varying sensitivity. For protection purposes, it should therefore be assumed that increments of exposure of a substance cause incremental responses in a similar way.

In particular, reproductive and developmental toxicity including neurotoxic effects on children should be of concern. Such effects have been demonstrated for several of the Stockholm POPs (dioxins, PCBs, DDT), as well as for organophosphates, pyretroids, carbamates, and metals such as lead and mercury. Recently, polybrominated diphenyl ethers have been added to the list of suspect substances. As an example, the model used for the WHO evaluation of lead effects ${ }^{6}$ assigns a loss of intelligence quotient (IQ) that is almost linearly related to the blood lead level above a threshold of around $3 \mu \mathrm{g} / \mathrm{dl}$, a level corresponding to the actual US 75 th centile for $1-5$ year old children. ${ }^{7}$ Indeed, low dose effects have

Abbreviations: POPs, persistent organic pollutants; IQ, intelligence quotient 
been demonstrated in laboratory animals according to a recent peer review, ${ }^{8}$ sometimes with linear dose-response relations, as for effects on anogenital distance, nipple retention, and prostate weight attributable to vinclozolin exposure of pregnant rats.

Against this background, I question the sufficiency of today's protective measures. If a large range of substances that exist in children can add up to an ongoing deterioration of IQ, there are good reasons for stronger protection, in addition to alleviating societal economic concerns. ${ }^{9}$ It is extremely difficult, and in practice impossible, to make a detailed assessment of the potential synergistic effects. A simple measure, however, is to introduce a provisional margin of safety, much the same way as the provision of an optional safety factor of 10 for children via the US Food Quality Protection Act. Such a margin would apply to adults and children alike and reduce the likelihood of injury from a multitude of substances causing exposures of long durations.

This consideration is added to the already existing peculiarities of the tolerable intakes set by various bodies, where "FDA action levels fall short of other federal agency standards of public health protection". ' Similar criticism has been raised earlier with respect to food dyes, for which FDA is allegedly lagging behind in recognising neurobehavioural assays as an essential aspect of drug testing, ${ }^{10}$ and for dioxins where the US EPA rejection of a low reference dose has been criticised. ${ }^{11}$ Also WHO evaluations seem to serve several masters at the same time, as in the lead evaluation. ${ }^{6}$ Here, one did not change recommended tolerable intakes. However, the evaluation group stated that " ...current dietary levels of lead have negligible effects on intellectual development but noted that food with high lead contents remain in commerce. The simulation model presented here can be used to evaluate the effects of any planned interventions." More debate concerning double talk in food safety seems highly warranted.

\section{REFERENCES}

1 Schafer KS, Kegley SE. Persistent toxic chemicals in the US food supply. J Epidemiol Community Health 2002;56:813-17.

2 United States Environmental Protection Agency. EPA's National Agenda to protect children from environmental health threats. (http://www.epa.gov/epadocs/child.htm\#agenda) (accessed 15 May 2002).

3 Erickson BE. Analyzing the ignored environmental contaminants. Environ Sci Technol 2002;36:140-5A.

4 Hovander L, Malmberg T, Athanasiadou I, et al. Identification of hydroxylated PCB metabolites and other phenolic halogenated pollutants in human blood plasma. Arch Environ Contam Toxicol 2002:42:105-17.

5 Silva E, Rajapakse N, Kortenkamp A. Something from "nothing" - eight weak estrogenic chemicals combined at concentrations below NOECs produce significant mixture effects. Environ Sci Technol 2002;36:1751-6.

6 WHO/IPCS. Safety evaluation of certain food additives and contaminants. WHO food additive series 44. Geneva: WHO/IPCS, 2000:308-9

7 Centers for Disease Control and Prevention. National report on human exposure to environmental chemicals. Atlanta, GA: March 2001:15-17. (http://www.cdc.gov/nceh/dls/report/results/Lead.htm)

8 Melnick R, Lucier $G$, Wolfe $M$, et al. Summary of the National Toxicological Program's report of the endocrine disruptors low-dose peer review. Environ Health Perspect 2002;1 10:427-31.

9 Grosse SD, Matte TD, Schwartz J, et al. Economic gains resulting from the reduction in children's exposure to lead in the United States. Environ Health Perspect 2002;110:63-9.

10 Weiss B. Vulnerability of children and the developing brain to neurotoxic hazards. Environ Health Perspect 2000;108 (suppl 3):375-81.

11 Pohl HR, Hicks HE, Jones DE, et al. Public health perspectives on dioxin risks: two decades of evaluations. Hum Ecol Risk Assess 2002; 8:233-50. 